\title{
COMO ANDA A EDUCAC̣ÃO SEXUAL DOS JOVENS
}

\begin{abstract}
RESUMO -O estudo revela o resultado de uma pesquisa realizada com 120 jovens estudantes de 04 instituições de ensino formal a nível de $2^{\circ}$. grau na cidade de Recife. $\mathrm{O}$ objetivo principal do trabalho foi verificar o que os jovens sabem sobre educação sexual e doenças sexualmente transmitidas. Os resultados evidenciaram que eles desconhecem as formas de prevenção controle e tratamento das doenças sexualmente transmitidas, estando portanto mais vulneráveis às mesmas. Relata ainda que as orientações sobre educação sexual emitidas aos jovens são oriundas principalmente de 2 grandes instituições Família e Escola.

Os colegas constituem também fonte de informação sobre sexo para a maioria dos jovens. Com base nos resultados da pesquisa, os autores formularam sugestões às famílias, escolas, instituições religiosas, aos jovens e à sociedade em geral.
\end{abstract}

ABSTRACT -The study discuss the findings of a research realized with 120 young students in four higs-schools in the city of Recife. The main objective of the study was to observe what the young people knows about sexual education and sexual transmissible diseases. The data identified that the young people unknow the means of prevention, control and treatment of the sexual transmissible diseases. Therefore, they are vunerable to them. The study also identified that all orientation about sexual diseases are given to the young people by the schools and families and they learn about sex life through their schoolmates. Based on the data research the authours proposed recomendation and suggestions to the families, schools, religions institutions, students and the society as a whole.

\section{INTRODUÇÃO}

Raramente a juventude tem sido alvo de atenção e de preocupação da sociedade. Hoje passa a ser vista como tema político-social e de saúde. Pensando nesta linha de ação, a Organização Mundial de Saúde proclamou 1985 como o ANO INTERNACIONAL DA JUVENTUDE adotando como lema "Juventude: hora de buscar, hora de entender". Com esta conotação, o jovem está sendo percebido como um portador da esperança e o futuro da humanidade. Tal visão precisa ser percebida por todos; assim o Ano Internacional da Juventude, poderá ser um marco na história do Brasil, na Nova República que se inicia no País devolvendo aos jovens de hoje - representando as crianças de ontem, que sobreviveram a todos os riscos ou formas de agressão física, psíquica, social e cultural, implantadas no País com a Revolução de 1964 - o direito de participação e criatividade, contribuindo assim para a construção de uma sociedade justa e fraterna.

Nesse processo participativo/efetivo, os jovens que atravessam uma crise psicológica, terão melhores condições de superá-la saindo vencedoras após terem do-

\footnotetext{
* Professora Assistente do Departamento de Enfermagem/CCS/UFPE.

** Enfermeiro do INAMPS-CE.

*** Professora Adjunta do Departamento de Enfermagem/CCS/UFPE e Enfermeira do Hospital Agamenon Magalhães-INAMPS-PE.
} 
minado seus problemas imediatos e incorporado os hábitos sadios de vida, fortalecendo o seu desenvolvimento, facilitando assim a sua iniciação na fase adulta. A posição do jovem no contexto social vai depender do tipo de sociedade na qual está inserido. Nas sociedades contemporâneas, ditas civilizadas, o jovem, é percebido como ưm ser constestante, irritável e irritante, incômodo, reformista e egoísta; considera-se o centro do universo, 'o umbigo do mundo". Associam-no ao sexo e a droga, vendo como um desafiante da sociedade dos adultos.

Já nas sociedades primitivas, ele é percebido como um ser essencialmente saudável, dotado de força e energia, capaz de ajudar a familia e a coletividade. O jovem portanto, ocupa posições diferentes, de acordo com o cenário que habita e do espaço que lhe é oferecido. Nas últimas décadas, a familia vem delegando grande parte de sua responsabilidade de socialização e educação do jovem às instituições formais. Esssa transferência de responsabilidade éjustificada pelo fato de que a maioria dos adultos saem da adolescência sem terem experimentado o processo do questionamento, que representa o elemento essencial para seu crescimento e maturidade, sentindo-se, portanto, impotente na orientação dos jovens, os quais são questionadores por excelência e quanto têm direito a voz, enfrentam os obstáculos, a ansiedade, a dúvida, o medo e a incerteza. Esse relato mostra a origem do atrito que existe entre alguns adultos e adolescentes. Essa maneira de ser de cada um, diferencia-os na sua forma de sentir, pensar e agir, bloqueando a interdependência que deveria ser saudável entre eles. Infelizmente, o sistema educacional formal, nem sempre está preparado para assuimir as responsabilidades delegadas pela familia, não of erecendo ao jovem as soluções esperadas para os problemas psicossociais e orgânicos de idade. 0 jovem portanto, vive o conflito, a incerteza e a necessidade de orientação, inclusive as referentes à espera sexual. Essa lacuna no conhecimento os coloca como um grupo vulnerável para contrair as doenças sexualmente transmitidas (DST) hoje assumindo índices alarmantes e tornando-se um desafio para as autoridades sanitárias em ãmbito nacional e internacional. Frente a esse problema, o governo através da Portaria Ministerial № 47 de 23 de janeiro de 1978, resolveu adotar normas específicas no combate às doenças transmitidas através do sexo. E nessa luta, percebe-se a necessidade de se dar uma nova dimensão ao ensino nas escolas, ressaltando os aspectos preventivos e curativos das doenças. Nessa perspectiva, a ação educativa visará essencialmente neutralizar no indivíduo os fatores de ordem social e cultural que nocivamente vêm contribuindo para $o$ alastramento das D.S.T principalmente entre os jovens, que pagam pesado tributo pela sua ignorância sobre 0 assunto e que é fomentada pela conotação pejorativa que a sociedade atribue a estas enfermidades.

\section{O PROBlema e A JUStificativa dO ESTUDO}

A incidência de D.S.T. está aumentando e o problema passa a assumir aspecto de uma verdadeira epidemia, acometendo a grande maioria dos jovens em todo mundo, nos últimos decênios. Os dados contidos na literatura revelam que na estatística mundial dos últimos 20 anos, a gonorréia aumentou em $200 \%$ no homem e 500\% nas mulheres. Mais pertubador ainda é saber que triplicou a proporção de adolescentes afetados. Os dados obtidos no centro de tratamento de Venerologia do Estado de Pernambuco, revelam que em 3 meses (janeiro, junho e novembro) do ano de 1984, a gonorréia acometeu 141 indivíduos do sexo masculino com idade superior a 15 anos, seguido do cancro venéreo simples com 48 casos, do linfogranuloma venéreo com 25 casos e da sífilis com 17 casos. Já em 1985, nos meses de janeiro, fevereiro, abril e maio foi registrado na faixa etária de 9 a 15 anos que a gonorréia acometeu 146 jovens, o linfogranuloma venéreo 22 , a sífilis, 36. Acima de 15 anos, foram registrados 65 casos de gonorréia, 22 de sífilis e 09 de linfogranuloma venéreo. Os dados acima revelam que a situação é bastante grave; apesar disso foi gratificante tomar conhecimento de que os governos estaduais estão encetando campanhas para debelar esses índices alarmantes de D.S.T. a exemplo do que vai fazer a Secretaria de Saúde do Rio Grande do Sul, a qual poderá utilizar na sua campanha de esclarecimento sobre as D.S.T., a música Mônica Tricomônica lançada em 1979 e proibida pela Censura Federal. A Campanha visa esclarecer os jovens a partir dos 15 anos de idade sobre os mecanismos de transmissão e as consequências das doenças venéreas. Há informações sobre AIDS (1985) no jornal Pulso que essa Secretaria atendeu no ano passado 52 mil pessoas portadoras de D.S.T. e informa também que anualmente são registrados no Estado cerca de seis mil casos de sífilis e 17 mil de gonorréia. Lembra ainda que esses números não incluem os atendimentos em hospitais e ambulatórios privados, não computados pela Secretaria de Saúde.

Associado intrinsecamente a esse fato, cita-se que a revolução sexual contemporânea, não se fez acompanhar de uma informação generalizada e racional sobre 0 assunto

Baseados nestes dados questionou-se:

- Será que os pais estão participando da educação sexual dos seus filhos.

- Será que o sistema educacional formal está emitindo orientações sobre educação sexual e sobre as doenças transmitidas por contato sexual?

- Qual será a informação que o jovem tem sobre sexo e D.S.T.?

- Será que se houver maior informação na família, escolas e comunidade sobre as D.S.T., sua prevenção e tratamento, ocorreria um delínio dessas doenças? 
- Será que se a educação sexual nas escolas for realizada por um profissional da área de saúde, a resposta dos jovens aos processos ensino aprendizagem será mais eficaz?

Tentando responder a estes questionamentos, os pesquisadores se propuseram a realizar um estudo enfocando as D.S.T., e comportamento do jovem frente a educação sexual e à enfermidade.

\section{OBJETIVOS}

- Identificar alguns padrões de comportamento social dos jovens, e de suas famílias, referentes à educação sexual.

- Investigar conhecimentos e atitudes dos adolescentes quanto ao sexo e experiência com D.S.T.

- Diagnosticar a participação da família, da escola e da Igreja no processo de ensino/ aprendizagem sobre sexo e D.S.T.

\section{REVISÃO DE LITERATURA}

As modificações anátomo-fisiológicas que ocorrem nos adolescentes, bem como as modificações na sua forma de pensar, sentir e agir, são fatores que justificam a necessidade de uma educação sexual para os mesmos, conduzindo-os a um respeito por sí mesmo e pelas pessoas do sexo oposto. A sexualidade é um dos aspectos mais difíceis de ser tratado porque os problemas sexuais não resultam dos adultos (FERRAPOTTI, 1984).

Para ISAEV (1979) a educação sexual em alguns países da Europa é obrigatória, sendo adotada em todas as escolas desde o período pré-escolar. Estretanto, é citado também, que em algumas regiões do mundo, inclusive em países europeus, a sexualidade representa um tabu. Assim é que mesmo na Suécia, onde se diz existir uma ampla liberdade sexual, a maioria dos adolescentes não têm oportunidade de conversar livre e sinceramente sobre sexo com os adultos. De outra forma, sabe-se que o amadurecimento sexual, entendido como a capacidade de reprodução, provavelmente esteja ocorrendo mais cedo no mundo contemporâneo do que antigamente. Reforçando o exposto, GOULD (1974) relata que a puberdade vem decrescendo paulatinamente, deixando o adolescente muito mais exposto, vez que adquire uma consciência muito mais precoce de sua importância sexual, consciência esta, que é rigorosamente promovida por "anunciantes que visam a carteira de consumidores de adolescentes" e conseqüentemente, a sua exploração sexual. As conseqüentes necessidades emocionais e intelectuais que automaticamente se manifestam nessa idade, podem surgir quando o ambiente social imediato - a família $\mathrm{e}$ a escola - podem estar mal estruturados ou mal equipados para atendê-los (CARBALLO, 1976). Por outro lado, lembre-se que a rápida mudança dos nossos dias tem sido considerado por muitos como uma importante fator accessório dos problemas da juventude na sociedade moderna. Embora a mudança tenha sido constante na história do homem, o seu ritmo está em rápida aceleração. Esse fenômeno de ritmo de mudança tem grande importãncia na maneira pela qual o indivíduo a percebe e a ela faz face.

Sociologicamente sabe-se que toda mudança gera crise, determinando no sistema e no indivíduo, instabilidade, desorganização social e pessoal. No mundo contemporâneo, testemunhamos importantes alterações nos papéis do homem e da mulher, agora menos polarizados que nunca. A dependência feminina tende a regredir rapidamente. A nudez deixou de ser tabu e a sexualidade foi superada; a atividade sexual elevou-se e a conotação sobre o sexo mudou passando do papel puramente procriador para o de satisfação das necessidades fisiológicas. Reforçando o exposto, GOULD (1974) diz que para a maioria dos jovens, o sexo passou a ser um divertimento inconsequaente, o que acarretou o crescimento dos índices das D.S.T. em todo mundo, gerando portanto, um problema crescente de saúde pública. O Ministério da Saúde relatou que entre as D.S.T., a gonorréia, a sífilis e a tricomoníase vem aumentanto progressivamente estando esta última acometendo as mulheres sexualmente ativas em torno de $10 \%$ (BRASIL, 1984).

E GOULD (1980) ainda salienta que em algumas partes do mundo, cada segundo que passa, uma, duas, três e até quatro pessoas estão contraindo sífilis ou gonorréia. Se a vítima tem a sorte de receber tratamento eficiente e imediato, a infecção talvez se revele na forma de um simples inconveniente passageiro. Mas, para um grande número de pessoas, entre as quais está inserido um grande número de jovens, as D.S.T. podem determinar a esterilidade humana e em casos extremos, até a morte. E para reforçar o exposto, cita ainda o mesmo autor que, anualmente ocorrem em todo o mundo mais de três milhões de casos de sífilis. Uma retrospectiva na história mostra que o aparecimento de D.S.T. eclodiu em alguns países da Europa, após a 2ª Guerra Mundial, chegando-se a citar a Inglaterra como um país promíscuo.

As familias foram dissolvídas, contribuindo para que houvesse a migração de jovens, que passaram a viver separados de seus lares, de seus empregos, de seus amigos, vivendo intensamente cada dia como se fosse o último. Nesse viver incluía-se a prática do sexo sem limite; aumentava portanto a promiscuidade poderosa aliada das D.S.T. As conseqüências tardias das D.S.T. recaem sobre as mulheres, nas quais o agente etiológico se espalha por outras partes do corpo (provocando inflamação das articulações, dos ovidutos, das membranas do coração e do célebro, salpingites gonocócices e até septicemias fulminantes).

As mulheres representam o elo mais perigoso e menos controlável do alastramento das infecções vené- 
reas, uma vez que as lesões se processam mais no interior do organismo. 0 diagnóstico das D.S.T. no homem é mais fácil, vez que os sintomas são óbvios (há eliminação do material purulento, dor e desconforto à micção) na gonorréia. Já na sífilis aparecem lesões no pênis, ponto de penetração dos germes, dando ao homem a confirmação de que algo está errado com o seu organismo.

Atualmente a incidência da sífilis e da gonorréia encontra-se na faixa etária de 18 a 24 anos, época em que estão no auge da atividade sexual, ocorrendo a freqüente troca de parceiros sexuais; são eles os responsáveis por cerca de $50 \mathrm{a} 80 \%$ de todos os casos de D.S.T., apesar de ser considerado o grupo mais sadio e que menos precisa de assistência médica. Outra forma de propagação das D.S.T. é realizada através de viagens de turismo e negócios, onde os homens, sentindo-se livres de inibições e restrições normais, procuram satisfazer suas necessidades sexuais. Também constitue forma de propagação das D.S.T. o relacionamento homossexual. O controle torna-se difícil. GUTHE (1971) ressalta que nas D.S.T. as atitudes sociais e psicológicas determinam até que ponto é possível individualizar e encontrar os contatos em decorrência da existência de tabus sobre $o$ assunto. As pessoas normalmente tendem a esconder as informações, sobretudo nas ocasiões de dificuldade. A licenciosidade se estende tanto ao comportamento heterossexual quanto ao homossexual e também a todas as camadas da sociedade e de profissionais. Tudo isso concorre para o recrudescimento. $\mathrm{E}$ o mesmo autor salienta que, nem sempre os jovens sabem como enfrentar o problema quando acometidos pela infecção venérea e nem tão pouco sabem como encontrar auxilio, constituindo un paradoxo da sociedade moderna. E afirma ainda que a média de vida do homem aumentou, sua vida sexual começa mais cedo e dura mais tempo, aumentando assim as possibilidades de disseminação das D.S.T. Ao mesmo tempo o progresso aumentou a possibilidade do encontro entre os dois sexos, em virtude da busca de trabalho pelas mulheres, que separadas de suas familias, romperam o elo da vida tradicional. As moças hoje concorrem com as prostitutas no mercado sexual, procurando o luxo da vida moderna. E CAUSSE (1975) afirma que a incidência nas D.S.T. nas grandes cidades é bem maior que na zona rural, sendo isto uma decorrência da industrialização, da tecnologia, do emprego feminino e do trabalhador migrante, reforçando assim o que foi exposto anteriormente. Aliado a esses fatores, é citado que houve um declínio do temor pela gravidez fora dos laços matrimoniais, justificado pelo uso de anticoncepcionais em larga escala. Paralelamente a todos esses eventos, têm havido alterações no ãmbito da própria família, no seu estilo de vida, na posição econõmica, na cultura e nos valores morais. Discorrendo sobre as consequências e custos das D.S.T., CAUSSE (1975) diz serem evidentes: a hospitalização, os tratamentos prolongados exigidos por complicações incapacitante ou agudas, sem citar as possibilidades de morte e dos casos que resultam em infertilidade, representando um pesado õnus para a coletividade e para a nação. Em comparação, todo programa de saúde que visa a erradicação da D.S.T. é economicamente vantajosa. GOULD (1980) afirma que o controle das D.S.T. representa um desagradável choque para as autoridades sanitárias, pois, presume-se que, com o advento dos novos métodos terapêuticos (penicilina, sulfas) ocorreria um decréscimo no seu índice ou seu desaparecimento, o que na realidade não vem acontecendo. Essa realidade é justificada pelo uso indiscriminado da auto medicação em doses insignificantes ou abandono do tratamento com o desaparecimento inicial dos sintomas. isso concorre para aumentar a resistência das bactérias aos antibióticos, favorecendo a invasão sistêmica da doença, concorrendo para que os efeitos lesivos da mesma, surjam tardiamente.

\section{METODOLOGIA}

É um estudo exploratório. A população foi constituída por 120 jovens estudantes de 4 colégios da cidade do Recife, em Pernambuco, sendo dois pertencentes a rede particular do ensino (colégio A e B) e dois ligados ao governo do estado (colégio $\mathrm{C}$ e $\mathrm{D}$ ). $\mathrm{O}$ colégio A of erece uma formação religiosa evangélica, enquanto que o colégio B segue a doutrina católica.

Para selecionar os jovens que participaram da pesquisa, os pesquisadores adotaram os seguintes critérios: - Em cada colégio seriam escolhidos 30 jovens que estivessem cursando o $2^{\circ}$. grau, compondo grupos de estudantes do sexo masculino e feminino.

- Os estudantes deveriam permanecer em uma sala indicada pela docência de estabelecimento de ensino; só então os pesquisadores, partindo da apresentação, entregariam os questionários e exporiam os objetivos do estudo.

Pretendia-se, inicialmente, que os estudantes selecionados, estivessem cursando a $1^{\mathrm{a}}$, $2^{\mathrm{a}}$. e $3^{\mathrm{a}}$. série do $2^{2}$. grau, ficando estabelecido que em cada uma das séries citadas estariam representadas por 10 alunos sendo que 5 seriam do sexo feminino e 5 do sexo masculino, constituindo então um total de 60 estudantes de cada sexo. Entretanto, em alguns colégios essa seleção foi impossível, como ocorreu no colégio $\mathrm{B}$, onde todos os estudantes pertenceram a $1^{\text {a }}$. série do $2^{\circ}$. grau e no colégio $\mathrm{C}$ a população foi constituída basicamente por estudantes de sexo feminino.

0 instrumento de medida, constou de um questionário composto de 18 itens os quais foram procedidos por uma mensagem emitida aos alunos pelos pesquisadores, um iten relacionado a definição de termos, dados familiares e dados de identificação pessoal (idade, sexo, estabelecimento de ensino, série e turno). Das 18 perguntas, 12 foram de questões fechadas, 4 abertas e 2 mistas. As primeira 6 questões visavam obter do jovem as suas fontes de informações sobre educação sexual. A $7^{\text {a }}$. questão averiguava o conhecimento que 
o jovem tinha sobre as D.S.T. A $8^{\mathrm{a}}$ questão buscava a informação sobrea acometimento ou não de D.S.T. A $9^{\mathrm{a}}$ e $10^{\mathrm{a}}$ questões complementavam a anterior e visava obter do jovem informações sobre a forma de conduta usada no combate à doença, bem como, as suas reações apresentadas durante este período. As $11^{\text {a }} \mathrm{e}$ $12^{\mathrm{a}}$ perguntas investigavam no jovem, os seus conhecimentos sobre as D.S.T. e os prejuizos que trazem ao organismo humano. As restantes referiam-se aos métodos preventivos das D.S.T.

Para aplicação dos questionários, foi enviada aos estabelecimentos de ensino um ofício, solicitando permissão à direção para que a pesquisa fosse realizada naquele local. 0 período de aplicação do instrumento durou 4 dias, ou seja 1 dia em cada colégio. Foi utilizado o turno da manhã, considerando ser este o horário de funcionamento do $2^{\circ}$. grau.

No tratamento estatístico adotou-se a tabulação manual dos 120 questionários e elaboração de tabelas contendo valores relativos e absolutos.

\section{ANÁLISE E DISCUSSÃO DOS DADOS}

Dos 120 jovens que participaram da pesquisa, 54 (45\%) são do sexo masculino e $66 \%$ (55\%) do sexo feminino. Dos 54 (45\%) estudantes do sexo masculino, 13 (11\%) estudam no colégio A, 14 (12\%) no colégio B, 09 (07\%) no Colégio C e 18 (15\%) no colégio D. Das 66 (55\%) jovens do sexo feminino encontrou-se que, 17 (14\%) estudam no colégio A, 16 (13\%) no colégio B, 21 (18\%) no colégio C $12(10 \%)$ no colégio $\mathrm{D}$.

Verificou-se que no grupo etário de 14 a 19 anos estão 105 (88\%) dos jovens e destes 51 (43\%) são do sexo masculino e 54 (45\%) do sexo feminino.

Ao serem investigados sobre as informações recebidas sobre educação sexual 105 (88\%) disseram ter recebido essa orientação, sendo que deste, 44 (37\%) pertenciam ao sexo masculino e 61 (51\%) do sexo feminino. Apenas 15 (12\%) disseram não ter recebido qualquer informação sobre $o$ assunto.

Evidenciou-se, também que a orientação que o jovem recebe sobre educação sexual tem origem nas 3 grandes Instituições - família, escola, igreja. 0 maior índice observado recai sobre a familia com $72(60 \%)$ abrangendo os dois sexos, seguindo-se da escola com 58 (48\%) e dos colegas com 34 (28\%). A participação da igreja tem sido pequena, observando-se que ocorreram em apenas $13(11 \%)$ dos casos.

Por ter sido observado que a educação sexual provén da família e da escola, acredita-se que o interrelacionamento entre essas duas instituições deveria ser mais efetivo e eficaz. Apesar da literatura afirmar que as familias da época contemporãnea estão delegando suas responsabilidades para o sistema educacional, observa-se no estudo que a familia ainda é responsável por grande parte desta tarefa. Infere-se que talvez a presença da mãe no lar seja um fator que justifique esses aspecto.

$\mathrm{Na}$ familia, a origem da informação recaiu pricipalmente sobre a mãe $43(36 \%)$, o pai $25(21 \%)$ e os irmãos 20 (19\%). Mais uma vez a mãe é vista como a principal responsável pela informação sobre a educação do jovem, principalmente o do sexo feminino uma vez que, numa população de 66 jovens ( $55 \%$ ) que participaram do estudo, 32 (48\%) receberam a orientação materna. Esse aspecto é reforçado por HULTEN (1976) quando diz que falar de sexo representa um assunto embaraçoso principalmente quando discutido em comum com jovens de ambos os sexos e considera ser mais prudente abordar 0 assunto com grupos separados por sexo.

$\mathrm{Na}$ escola a orientação recaiu principalmente sobre o professor $56(47 \%)$, seguindo dos profissionais de saúde com 21 (18\%). Esses dados mostram a importãncia que deve ser dada a preparação do professor, no que diz respeito à educação sexual, vez que são os mais procurados devido à convivência e à confiança. De outro modo, a indicação de profissionais de saúde nos colégios é também importante porque eles têm a formação específica sobre o tema. Esse fato é reforçado por CARBALLO (1976) quando diz que "os jovens adquirem do meio a percepção de si mesmo. Eles se orientam por aquilo que os outros dizem, pela maneira de reagirem aos seus impulsos, na forma de tratá-los, no modo de ajudá-los a se ajustarem às novas necessidades".

A orientação educacional na igreja recaiu principalmente sobre os grupos da própria instituição (grupos de jovens e grupos de casais) com 18 (15\%) seguida de $12(10 \%)$ referentes aos conferencistas convidados. A particação dos ministros religiosos foi baixa

Questiona-se se essa baixa incidência está associada à falta de preparo sobre 0 assunto determinado pela formação recebida no Seminário, onde havia a quase proibição do relacionamento interpessoal com o sexo oposto pois somente nas últimas décadas, a igreja tenta acompanhar as mudanças sociais.

Um aspecto que chama atenção na educação sexual, é que grande parte da orientação é buscada junto às colegas de escola e de lazer. Interroga-se a ocorrência desse fato não se deve à indentificação com a própria idade, o sistema de valores da adolescência, da forma de comunicação, da convivência e da própria experiência vivenciada nesta época marcada pelas descobertas?

Parece que essa indagação foi justificada quando os dados mostram que apenas $23 \%$ dos jovens do sexo masculino e $23 \%$ do sexo feminino procuram os pais para remover dúvidas sobre educação sexual.. Em segundo lugar, o esclarecimento e dúvidas é realizado junto aos colegas, com 33 (28\%) dos jovens de ambos os sexos. Os professores foram citados com 31 (26\%) para os dois sexos. Um grupo de jovens (6\%) ou que perma- 
nece na dúvida augumentando timidez e vergonha de falar sobre $o$ assunto. Observou-se que para isto, a literatura é pouco procurada (6\%) pelos jovens.

Quase a totalidade da amostra (93\%) tem conhecimento sobre D.S.T. e destes 50 (42\%) pertenciam ao sexo masculino e 61 (51\%) ao sexo feminino. Apenas 9 (7\%) desconhecem o assunto. Das respondentes que afirmam conhecer as D.S.T., 65 (54\%) apontaram a sífilis, $42(35 \%)$ a gonorréia, 21 (18\%) o cancro mole e 21 (18\%) a AIDS. Esta última, citada com um percentual bem elevado em comparação com as demais. Sabese que vem sendo já bastante difundida, o que vem mostrar a importãncia desempenhada pelos meios de comunicação de massa que ultimamente tem registrado casos de sua contagiosidade e de suas conseqüências.

No jornal Pulso que publica assuntos da classe médica informa que "dois milhões de americanos sofrem da Síndrome da Deficiência Imunológica Adquirida, conforme afirmado ao The Olsener, de Londres, pelo descobridor do vírus, Dr. Robert Gallo. 0 número é 10 vezes maior que o oficialmente anunciado pelas autoridades americanas e, dentro de dois anos, a AIDS fará igual número de vítimas entre os europeus. Portanto o mal se estende e se difunde entre os povos." (AIDS, 1985a).

O Prof. Mário Barreto no Simpósio sobre AIDS, realizado no Rio de Janeiro, citou que os casos aparecem em progressão geométrica e hoje, só no eixo Rio-São Paulo, já foram registrados 260 portadores de AIDS.

Com relação a experiência do jovem com D.S.T., 7 (6\%) do sexo masculino afirmaram já haver contraído, enquanto que 47 (39\%) do mesmo sexo, negaram ter sido acometidos. As 66 (55\%) respondentes do sexo feminino não viveram esse tipo de experiência. $\mathrm{E}$ para validar que os dados acima referidos, se aplicam mais ao sexo masculino, MAUREL em trabalho de pesquisa realizado em Mar del Plata, conclui que o grupo de positividade de sífilis atingiu o grupo de 15 a 29 anos com predomínio entre os homens (60\%). Os 7 (6\%) jovens que contrairam as DST, ao serem questionados sobre os sintomas apresentados, citaram, por unanimidade, a eliminação de secreção purulenta pelo canal uretral, dor e ardor à micção, adnamia, somente um jovem referiu ter apresentado pico febril nos estágios precoces da doença. Ressalta-se que a ausência de sintomas, constitue um dos maiores obstáculos para o combate às D.S.T.

Um dos aspectos que chama a atenção são as medidas adotadas pelos 7 (6\%) dos jovens que foram acomentidos de DST entre os 120 de estudo. Dessa população acometida (43\%) afirmou ter procurado os pais aos primeiros sintomas, $29 \%$ disseram ter procurado o médico e $28 \%$ se auto medicaram sendo un deles por indicação de amigos e outros por indicação de vendedores de farmácia. Inqueridos sobre as reações apresentadas quando acometidos pelas D.S.T. $86 \%$ dos jovens, disseram apresentar medo e $14 \%$ sentiu nojo. No que se refere a opinião dos jovens sobre prejuizos determinados pela D.S.T. $39 \%$ do sexo masculino e $54 \%$ do sexo feminino afirmaram acreditar nos danos que podem causar ao indivíduo, enquanto que $7 \%$ não acreditam nessas conseqüências. Foi dito por um jovem que essas conseqüências só podem ocorrer na velhice. Interrogados sobre quais as conseqüências que as D.S.T. podem determinar no indivíduo $24 \%$ dos jovens do sexo feminino e $18 \%$ do sexo masculino disseram traser danos mentais, orgãnicos e sociais ao acometido. Ja 7\% acreditam que a pessoa com D.S.T. sofre humilhação, fica com a "consciência doendo", fica complexado e com medo. Outros $8 \%$ citaram esterilidade e impotência como uma consequuência e $7 \%$ falaram em morte.

A constatação de que somente $5 \%$ jovens do sexo feminino mantém contato sexual, contradiz o citado na literatura consultada, que afirma estarem os jovens concorrendo no mercado com as prostitutas, procurando satisfazer o luxo da vida moderna. Percebe-se pelos resultados que a mulher continua sendo educada para uma vida sexual ativa após o casamento e continua a seguir neste aspecto, a forma tradicional de educação. Já os homens, pelo sistema machista implantado na sociedade, são iniciados em atividades sexuais desde cedo, estando, portanto, mais vulneráveis as D.S.T.

Com relação aos cuidados que os jovens adotam após a relação sexual, $28 \%$ do sexo masculino e $5 \%$ do sexo feminino tomam banho $21 \%$ do sexo masculino apresentam micção; $15 \%$ do sexo masculino 5\% do sexo feminino lavam os órgãos genitais após 0 ato.

Um aspecto que chama atenção foi quanto ao tipo de parceiro procurado, sendo que $38 \%$ dos respondentes de ambos os sexos que têm vida sexual ativa afirmaram manter relação sexual como a (o) namorada (o), enquanto que $25 \%$ dos homens procuram prostitutas e $39 \%$ mantém o relacionamento com alguém indicado por amigos. Uma das jovens entrevistadas mantém relações sexuais com o esposo. Baseado nos dados relatados, interroga-se: a ocorrência dos fatos de se procurar a namorada, não se deve ao medo de se contrair as D.S.T.? Com esse fato (ter medo), não estariam também se precavendo da rejeição imposta pelos amigos, como foi citado por alguns dos respondentes? Deve-se considerar neste aspecto o lado afetivo existente entre os namorados? Discordando desse último questionamento, dois jovens referiram ser contra a prática do sexo com a namorada pois acreditam que o respeito deve ser iniciado desde cedo. É interessante notar ainda que os jovens se preocupam com as condições de saúde do seu parceiro, ficando detectado no estudo que entre os 61 jovens com vida sexual ativa, $87 \%$ deles disseram procurar obter informações sobre as condições de saúde do seu parceiro e $13 \%$ negam esse interesse, o que leva a crer que estes jovens desconheçam as conseqüências das D.S.T. Indaga-se: isso não poderia justificar uma necessidade urgente de educação sexual? 
Entre os métodos anticonceptivos utilizados pelas 61 jovens com vida sexual ativa, $21 \%$ referiram usar a "camisa de vênus", $8 \%$ usam pílulas anticoncepcionais, $49 \%$ desconhecem os métodos, e $2 \%$ usam métodos de ovulação (tabela). Um dos jovens referiu que se auto medica com "comprimidos de antibióticos 2 horas antes e 4 horas após ato sexual". Chamando a atenção para esse último dado a Organização Panamericana de Sáude, em 1978, enfatizou que o uso inadequado de antibióticos(excesso ou doses incompletas) vem contribuindo com o alto índice das D.S.T. Esse uso indiscriminado deve-se ao fato da falta de controle na venda do produto, conduzindo o jovem a se medicar e a realizar consultas com o pessoal não médico, concorrendo, assim para a resistência dos germes.

Os dados expostos acima sobre os anteconceptivos confirmam a posição de GAUDERER (1984) que afirma "os jovens têm pouco ou nenhuma informação sobre contraceptivos". Entre os métodos preventivos indicados pelos 120 jovens, contra as D.S.T, citaram a utilização de locais higiênicos (motéis), não usar banheiro público $21 \%, 13 \%$ indicam o uso da "camisa de venus", $12 \%$ salientaram a necessidade de exames médicos periódicos, $4 \%$ indicam o uso de medicação e $7 \%$ informaram não saber qualquer dado sobre prevenção. Esses dados revelam que os jovens estão despreparados no que se refere a educação sexual, pois somente $57 \%$ responderam este item ficando $43 \%$ sem qualquer resposta. As sugestões propostas por $67 \%$ da população do estudo sugeriram a implentação de:

\section{Educação sexual}

- deveria ocorrer das seguintes formas:

- que os pais sejam treinados sobre 0 assunto para poderem atender as necessidades de seus filhos.

- que o governo realize campanhas sobre as DST e sexo

- que haja aulas de educação sexual em todas as escolas preparando os jovens para a atividades sexual sadia

- que nas escolas tenha um orientador especialista em educação sexual

- que os órgãos de comunicação de massa (jornal, TV, rádio) incorporem a necessidade de educar os jovens

\section{Revisão de saúde}

\section{- procurando o médico \\ - realizando exames.}

\section{Sexo sadio}

- "que os jovens não encontrem no sexo apenas uma fonte de prazer; deve ser feito com amor uma vez que foram criados por Deus".

- "não praticar o sexo só com o instinto, como animal"

- que a relação sexual só aconteça no casamento

- evitar contato com prostitutas

\section{Realização de estudos com esse tema}

- que seja realizada pesquisa idêntica a relatada, com universo maior dando ao jovem a oportunidade de expressão

- que esse estudo seja divulgado.

A maioria das sugestões apresentadas, revelam que o jovem "infelizmente participa pouco do processo educativo ao qual está sujeito. A sua participação pouco do processo educativo ao qual está sujeito. A sua participação é de ouvinte, onde lhe é proposto assimilar ensinamentos tradicionais, que muitas vezes se chocam com sua natureza inovadora e constestadora (GAUDERER, 1984)

\section{CONCLUSÕES E RECOMENDAÇÕES}

A partir do que foi exposto pode-se concluir que: - os jovens têm um espírito aberto, carentes do saber e que se preparados são mais capazes de apreciarem os princípio básicos dos cuidados primários de saúde, fazendo o seu auto cuidado. A sua participação neste nível representa um dos instrumentos de ajuda, para a concretização da pretendida saúde para todos no Ano 2000.

- os jovens estão despreparados na sua educação sexual, havendo uma lacuna dessas informações nas principais instituições onde convive - familia, escola e igreja. Se isto for sanado, os jovens serão ajudados a levar uma vida sexual sadia.

- uma das maiores buscas à suas dúvidas recai sobre os colegas que também vivem a desinformação em educação sexual, não estando portanto em condições de esclarecer e às vezes, gerando informações incorretas. - apesar dos resultados revelarem uma atenção dos pais (especialmente da mãe) no que se refere a educação sexual dos jovens, sentiu-se no estudo que não há uma liberdade de diálogo entre pais/filhos, aspecto esse sentido especialmente nas sugestões emitidas pelos jovens. Essa necessidade faz gerar conflitos, bloqueio na comunicação, busca de informações em outras fontes

-0 estudo comprovou que a falta de educação sexual desenvolve no jovem sentimento de culpa e de medo quando acometidos de DST, conduzindo-os a buscar auxílio junto a colegas e pessoas não credenciadas para realizar tratamento específico, escondendo nos momentos de dificuldade as informações necessárias ao combate dos agentes transmissores.

- a formação sexual dos jovens está alicerçado no modelo tradicional paternalista, sendo a mulher mais orientada para exercer a atividade sexual após o matrimônio, enquanto o homem, logo cedo é iniciado na prática sexual, estando, portanto, mais exposto ao contágio de DST - Fundamentando-se nas conclusões, recomenda-se: 


\section{Aos Jovens}

- que externalizem seus pensamentos e dúvidas procurando ocupar no contexto o seu espaço e exigindo atenção para a solução dos seus problemas.

- que procurem participar ativamente das atividades educativas organizadas pela escola, igreja e comunidade.

- que fundem associações para jovens, onde os mesmos terão seu espaço garantido para debates, buscando também aí, soluções para os problemas da juventude.

- que se aproximem de seus pais e tentem dialogar francamente, percebendo-os não como pessoas antigas, mas como elementos que foram bloqueados durante sua juventude.

\section{Aos pais}

- que procurem se entender a sí mesmo, conhecendo o seu acervo, suas limitações e suas emoções para poder lidar, conhecer, entender e compreender os jovens. - que procurem se atualizar em educação sexual afim de que possam participar na orientação sexual de seus filhos.

- que procurem estabelecer um relacionamento interressoal com seus filhos, procurando discutir os problemas de sua idade e orientando na saída da crise.

\section{Aos professores}

- que os prof essores adotem uma atitude positiva na orientação sexual dos jovens, vez que são elementos de busca nas dúvidas e nos exclarecimentos sentidos pelos mesmos.

- que procurem aperfeiçoar seus conhecimentos sobre educação sexual.

\section{Às escolas}

- que seja possibilitado ao jovem a oportunidade de receber informações mais detalhadas do que as contidas nos programas escolares.

- que a orientação sexual seja iniciada desde o $1^{\circ}$ grau.

- que contratem profissionais de saúde para ministrar as orientações relacionadas a educação sexual e DST. - que seja dado nos programas um enfoque multidisciplinar problemas da sexualidade e DST.

- que estabeleçam uma integração com a familia através de reuniões, debates, documentos, cursos onde as soluções aos problemas da sexualidade sejam debatidos em conjunto.

- que os debates iniciados intra muros das escolas, sejam ampliados atingindo a comunidade.

\section{Às instituições religiosas}

- que fortaleçam e/ou fundem organizações de grupos de jovens desenvolvendo neles o compromisso com sua saúde e com a saúde da coletividade.
- que os ministros participem mais efetivamente da educação sexual da juventude com base na realidadè da época.

\section{Aos governantes}

- que tornem compulsória a educação sexual nos estabelecimentos de ensino, desde o 1 . grau.

- que melhorem as estruturas dos serviços de vigilãncia epidemiológica das DST, atualizando e divulgando os dados estatísticos sobre os mesmos.

- que criem programas de assistência médica especial ao grupo de risco de 15 a 24 anos.

- que adotem campanhas contra as DST, divulgando na coletividade suas causas e suas conseqüências.

\section{Às universidades}

- que deêm maior atenção ao ensino das DST preparando os profissionais de saúde para atuarem junto aos jovens.

- que realizem pesquisas sobre o tema, procurando descobrir os fatores sociais e psicológicos que norteiam a comunidade e a população alvo.

\section{À sociedade}

- que passe a olhar o jovem como um elemento capaz de contribuir para a produção da nação, permitindo ao mesmo ser sujeito e protagonista da sua história. - que forneça apoio ao jovem permitindo-lhe a livre expressão de idéias.

\section{Ao sistema de comunicação}

- que a comunidade de massa (TV, Rádio, Jornais, revistas) aborde os temas ligados à educação sexual e DST, apresentando problemas e soluções dentro da sua característica peculiar de linguagem.

\section{REFERÊNCIAS BIBLIOGRÁFICAS}

1 AIDS: o mal se estende. Pulso, Rio de Janeiro, 25 (585): 3, maio $1985 \mathrm{a}$.

2 AIDS: Pulso, Rio de Janeiro, 25 (585): 5, maio 1985b.

3 ALFEI, Beatriz \& MAUREL, Daniel Luis. Investigacíon de contactos en enfermos de sifilis en Mar del Plata, Argentina, Boletin de la Oficina Sanitaria Paramericana, Washington, 95 (3): 253-9, Sept. 1983.

4 ALLAIN - Regnault, Martine. Comunicação nos dois sentidos. A saúde do Mundo, Genebra: 21-2, jan./fev. 1985.

5 BRASIL. Ministério da Saúde. Assistência integral à saúde da mulher bases de ação programática. Brasília, 1984.

6 CAMPOS, Dinah Martins de. Psicóloga da adolescência: normalidade e psicopatologia. 7 ed. Petrópolis, Vozes, 1982.

7 CARBALLO, Manuel. Em busca de identidade. A Saúde do Mundo, Genebra: 26-8, dez. 1976.

8 CAUSSE, O. A maçã Bichada. A Saúde do Mundo, Genebra: 3-7, maio 1975.

9 CHAINA, Miguel Shadid \& Jimenèz, Edgar Garrido. Diagnostico de neisseria gonorerihoere en la mujer mediante el exame de varias regiones anatomicas. Boletin de la Oficina $\mathrm{Sa}-$ nitaria Panamericana, Washington, 94 (1): 45-51, ene. 1983.

10 CONTRAGonorréia: eradacil e monica tricomônica.Pulso, Rio de Janeiro, 25 (585): 3, maio 1985. 
11 DOENÇAS venéreas. $A$ Saúde do Mundo, Genebra: 26, jun. 1969.

12 EDITORIAL: doenças sexualmente transmissíveis.Revista Brasileira de Medicina, Rio de Janeiro, 35: 1, maio, 1978

13 FERRAPOITI, Nydia Gomes. Educación para la salud en la auolescência relato de uma experiência. Boletin de la Oficina Sanitária Panamericana, Washington, 97 (3): 240-9, Sept. 1984.

14 GAUDERER, E. Christian. Adolescência, os jovens e nós: uma visão pessoal. Jornal Brasileiro de Medicina, Rio de Janeiro, 47 (6): 15-38, dez. 1984.

15 GOULD, Donald. Em busca de uma nova resposta final. $A$ Saúde do Mundo. Genebra: 28-31, jun. 1974.

16 As doenças do contacto sexual. A Saúde do Mundo, Genebra: 23-5, nov. 1980.

17 _Em busca de uma nova resposta final. A Saúde do Mundo, Genebra, 28-31, jun. 1974.

$18 \_0$ flagelo de vênus. A Saúde do Mundo, Genebra: 8-11, nov. 1976.

19 GUTHE, Thorstein. A juventude em perigo. A Saúde do Mundo, Genebra: 30-5, out. 1971.

20 HULTÉN, May. Removendo tabus. A Saúde do Mundo, Genebra: 22-5, dez. 1976 .

2] ISAEV, D.N. A educação Sexual. A Saúde do Mundo, Genebra: 20-3, out. 1979.

22 JARAMILLO, Orlando et alii. Costa Rica: programa para el control de las enfermedades de transmission sexual. Boletin de la Oficina Sanitaria Panamericana, Washington, 86 (2) 131-40, feb. 1979 .
23 LIBERADA música que alerta jovens para o uso indevido do sexo. Diário de Pernambuco, Recife, 26 maio 1985. Últimas Notícias, p. A 16 , c. 3 .

24 MAHLER, Half dan. Juventude sadia: nosso bem mais precioso. A Saúde do Mundo, Genebra: 3, jan./fev. 1985.

25 OFTALMIA, gonocócica del recien nacido. Boletin de la Oficina Sanitaria Panamericana,, Washington, 85 (6): 553-4, dic. 1978.

26 PARIJS , Luk G. Nada a esconder. A Saúde do Mundo, Genebra: 20-5, maio 1975.

27 PIERSON, Donald. Isolamento e contato. In:__. Teoria e pesquisa em sociologia. 10. ed. Rio de Janeiro, Melhoramentos, 1967. Cap. 11, p. 143-75.

28 PODAIR, Simon \& HARRIS, Mortimer. Las enfermedades venéreas. México, Centro Regional de Ayuda tecnica, 1970

29 RODRIGUES, Luzia. A hora e a vez da juventude. A família Cristã, São Paulo, 51 (589): 4-5, jan. 1985.

30 SECRETARIA NACIONAL DE PROGRAMAS DE SAÚDE - Divisão Nacional de Dermatologia Sanitária. Portaria $n^{\circ} \mathrm{s} 22$, de 18 de julho de 1978: Norma técnicas ...s.n.t. 7f. mimeogr.

31 SOWMINI, O.N. Um método novo e imperativo. A Saúde do Mundo, Genebra: 8-10, maio 1975.

32 SUPLYCY, Marta. A sexualidade do deficiente. In: .Conversando sobre sexo.. 7 ed. Petrópolis, Vezes, 1983. Cap. 9 , p. 331-7.

33 USO inadecuado de antibióticos dificulta el control de enfermedades venereas. Boletin de la Oficina Sanitária Panamericana, Washington, 85 (4): 362-3, out. 1978. 